\title{
PRÁTICAS E INFLUÊNCIAS DAS ESCOLINHAS DE FUTEBOL NA CARREIRA DE ATLETAS PARAIBANOS QUE CHEGARAM A SELEÇÃO BRASILEIRA
}

\author{
MELO, Manoel Luis ${ }^{1}$ \\ NUNES, Tamires Fernanda Barbosa ${ }^{2}$ \\ RODRIGUES, Alejandro Martins ${ }^{2}$
}

\begin{abstract}
RESUMO: A Paraíba tem se destacado nos últimos anos como celeiro de atletas que iniciaram suas carreiras nas escolinhas de futebol e se destacaram atuando por grandes clubes do Brasil e do exterior, sendo posteriormente convocados para a seleção brasileira. O presente influências que as escolinhas de futebol exerceram na carreira dos atletas paraibanos que chegaram à seleção brasileira, através de uma revisão bibliográfica de natureza exploratória. A história de atletas paraibanos que chegaram à seleção brasileira teve início com os atletas Índio (Ex - Flamengo), Assis Paraíba (Ex - Esporte Clube do Recife) e Rinaldo (Ex - São Paulo), que mesmo sem frequentarem as escolinhas de futebol foram destaque nos clubes em que atuaram nos anos de 1950 a 1990 . Na sequência, outros atletas conseguiriam o mesmo feito, a exemplo de Junior (Ex - Flamengo), Marzinho (Ex - Vasco da Gama), Marcelinho Paraíba (Ex - São Paulo), Fabio Bilica (Ex - Vitória da Bahia) e mais recente, Givanildo Hulk (Ex Vitória). A trajetória de sucesso dos atletas paraibanos até chegar à seleção brasileira nos levou a questionar sobre qual a importância das escolinhas de futebol na formação de atletas paraibanos que chegaram a Seleção Brasileira? De modo geral as escolinhas tem cumprido seu papel na formação e desenvolvimento dos novos atletas para o futebol brasileiro, como pode se constatar no exemplo da Paraíba que tem revelado vários atletas que chegaram à seleção brasileira.
\end{abstract}

Palavras-Chave: Paraíba. Escolinhas de Futebol. Seleção brasileira.

RESUMEN: Paraíba se ha destacado en los últimos años como granero de atletas que comenzaron sus carreras en las escuelas de fútbol y se destacaron actuando por grandes clubes de Brasil y del exterior, y muchos de los cuales fueron convocados más tarde a la selección brasileña. Este estudio tiene como objetivo mostrar las prácticas e influencias que las escuelas de fútbol reproducen en las carreras de los atletas paraibanos que llegó a la selección brasileña, a través de una revisión de la literatura de naturaleza exploratoria. La historia de atletas paraibanos que llegó a la selección brasileña comenzó con los atletas Índio (Ex - Flamengo), Assis Paraiba (Ex - Reef Club Sport) y Rinaldo (Ex - Sao Paulo), que aun sin haber ido a las escuelas de fútbol fueron destaque en los clubes que actuaron en los años 1950 a 1990. En la secuencia, otros atletas han logrado la misma hazaña, ejemplo Junior (Ex Flamengo), Marzinho (Ex - Vasco da Gama), Marcelinho Paraíba (Ex - Sao Paulo) Fabio Bilica (Ex - Bahía Vitória) y más recientemente, Givanildo Hulk (Ex - Victoria). La historia de éxito de los atletas paraibanos para llegar a la selección brasileña nos condujo a la pregunta ¿cuál es la importancia de las escuelas de fútbol en la formación de paraibanos atletas que llegaran a la selección brasileña? En general, las escuelas de fútbol han cumplido con su papel en la formación y desarrollo de los atletas jóvenes para el fútbol brasileño, como puede verse en el ejemplo de Paraiba ha puesto de manifiesto varios atletas que vinieron a la selección brasileña.

Palabras Clave: Paraíba. Escuelas de Fútbol. Selección brasileña.

\section{INTRODUÇÃO}

A Paraíba tem se destacado no cenário do futebol nacional nos últimos anos pelos atletas que atuam por grandes clubes do Brasil e do exterior, e até pela seleção brasileira. Alguns desses atletas, a exemplo de Índio, Assis Paraíba, Rinaldo Fernandes, Junior e Mazinho , conseguiram esse feito algumas

\footnotetext{
${ }^{1}$ Universidade Federal da Paraíba.

${ }^{2}$ Universidade Federal de Pelotas
} 
décadas atrás iniciando suas carreiras nos chamados campos de várzea ou nas categorias de base dos clubes locais e de fora do estado. Outros mais recentes, como Marcelinho Paraíba, Fábio Bilica e Hulk, foram formados em escolinhas de futebol e seguiram o mesmo caminho dos seus antecessores.

A trajetória de sucesso dos atletas paraibanos até chegar à seleção brasileira nos levou a questionar sobre qual a importância das escolinhas de futebol na formação de atletas paraibanos que chegaram a Seleção Brasileira?

As escolinhas de futebol surgiram após a Copa de 1986, quando muitos especialistas da área perceberam a necessidade de se formar futuros atletas com qualidades físicas diferenciadas a fim de suprir as deficiências notadas nesta competição. Segundo Bielinsky (s/d), o surgimento das escolinhas deu-se devido à redução das condições naturais para a prática livre e espontânea do futebol e com a formalização de uma atividade informal. Na Paraíba essa realidade não foi diferente, muitos atletas formados nas escolinhas de futebol acabaram conquistando o Brasil e o mundo, sendo convocados para a seleção brasileira e dando aos paraibanos a honra de ter entre os atletas mais qualificados do país alguns de seus filhos talentosos.

\section{HISTÓRIA DE ATLETAS PARAIBANOS QUE CHEGARAM À SELEÇÃO BRASILEIRA}

Esse estudo procura mostrar a história de atletas paraibanos que se destacaram por grandes clubes do Brasil e do mundo e que acabaram chegando à seleção brasileira, alguns tendo conseguido esse efeito quando ainda não existiam escolinhas de futebol, como foi o caso de Índio (Ex - Flamengo), Assis Paraíba (Ex - Esporte Clube do Recife) Junior (Ex - Flamengo), Marzinho (Ex - Vasco da Gama) e Rinaldo (Ex São Paulo), que mesmo sem frequentarem as escolinhas foram destaque nos clubes em que atuaram nas de 1950 a 1990.

Chegar à elite do futebol brasileiro, inclusive chegando à seleção brasileira em um tempo em que o futebol era carente da estrutura que tem atualmente, ainda mais se tratando de atletas pertencentes a um dos estados mais pobres da federação, como sempre foi considerada a Paraíba, parece algo impossível de se acreditar. No entanto, muitos conseguiram chegar à seleção brasileira com méritos. Mas de acordo com alguns relatos obtidos através de familiares e/ou matérias de jornais, poucos foram os que conseguiram tirar vantagem da carreira futebolística, pois naquele tempo o futebol não tinha a valorização que tem nos dias atuais.

Dos atletas formados nos chamados campos de várzea, Índio foi um dos primeiros a deixar a Paraíba para tentar a vida em outros campos do Brasil e conquistar o sucesso, sendo um dos primeiros atletas paraibanos a chegar à seleção brasileira. Segundo Toscano ${ }^{3}$, o garoto Aloísio Francisco da Luz (Figura 1), nascido em 01/03/1931, saiu de Cabedelo para residir no Rio de Janeiro à procura de uma vida melhor. Aos dez anos de idade já trabalhava ao lado de seus familiares sem, contudo, deixar de jogar suas peladas. A fisionomia indígena deu-lhe o apelido que o tornaria reconhecido para o resto da vida: Índio.

${ }^{3}$ Toscano, Eudes Moacir, 2007.

Nucleus,v.13,n.2,out.2016 
Figura 1 - Atleta Índio na Seleção Brasileira.

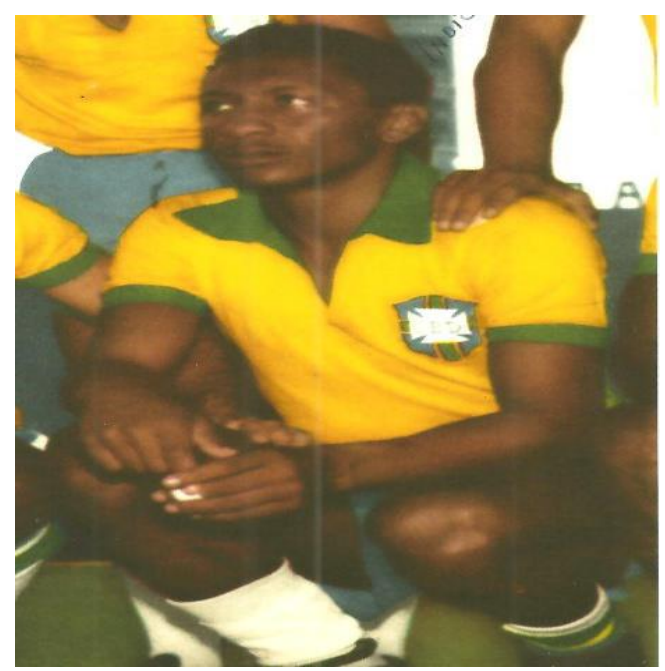

Fonte: Arquivo CBF, 2011.

Índio despontou no Flamengo durante o campeonato de 1948, sendo rapidamente incorporado ao time principal pelo qual atuou durante oito anos. Em 1953 foi convocado para a seleção brasileira e no ano seguinte participou da Copa do Mundo realizada na Suíça. Índio atuou nove vezes com a camisa da seleção brasileira e marcou quatro gols. Mesmo não conquistando nenhum título com a seleção canarinho, teve uma contribuição importante na conquista do mundial de 1958.

Em 1957 foi negociado ao Sport Clube Corinthians Paulista, no qual permaneceu até 1959, quando saiu para jogar na equipe do Espanhol de Barcelona, lá permanecendo até 1965, onde se destacou pela sua velocidade e os gols marcados em diversos campeonatos que disputou. Em 1965 retornou ao Brasil, encerrando a sua carreira no América Futebol Clube do Rio de Janeiro ${ }^{4}$.

Outra história parecida com a de Índio foi a de Assis Paraíba (Figura 2). Natural de Campina Grande - PB, Assis era oriundo de uma família envolvida com o futebol profissional, caso dos irmãos Zé Lima e Valdeci, que defenderam os principais clubes paraibanos. Iniciou a sua carreira atuando pelo Treze na década de 70, de onde saiu depois para defender o Tiradentes do Piauí, que na época era a grande sensação do futebol nordestino. Posteriormente, o atleta foi para o Sport Recife, oportunidade em que acabou sendo convocado para a seleção brasileira, em 1979. Em seguida, deixou o futebol brasileiro e foi para a Arábia Saudita, onde atuou por três temporadas.

Figura 2 - Assis Paraíba em apresentação pela Seleção Brasileira.

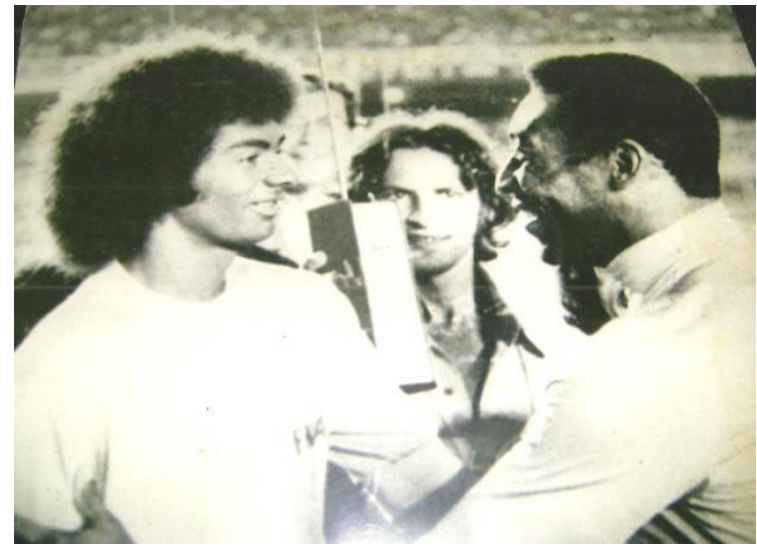

Fonte: Arquivo da CBF, 2011.

\footnotetext{
${ }^{4}$ Idem, 2007.
} 
As histórias de Índio e Assis Paraíba talvez sejam os exemplos mais clássicos de atletas que iniciaram suas carreiras fora das escolinhas de futebol e conseguiram a façanha de numa época com poucas oportunidades, se comparado aos dias atuais, saírem da Paraíba, e se destacar no cenário do futebol nacional. Por isso, ambos são considerados pioneiros na convocação de atletas paraibanos que para a seleção brasileira.

Seguindo a trilha desse pioneirismo, Antônio Rinaldo Gonçalves (Figura 3), ou simplesmente Rinaldo, foi outro atleta que iniciou sua carreira nas categorias de base do Campinense clube e, como seus antecessores também se destacou no futebol nacional e internacional, tendo igualmente chegado à seleção brasileira. Nascido coincidentemente no dia 31 de outubro em Campina Grande - PB, Rinaldo começou sua carreira no Campinense Clube, tendo depois atuado pelo seu maior rival, o Treze Futebol Clube. Entretanto, o atleta ganhou fama e reconhecimento defendendo o Santa Cruz do Recife, sendo considerado um dos principais destaques do clube em todos os tempos. No final dos anos 80 , o atleta teve seu passe negociado com o Fluminense do Rio de Janeiro, clube que o revelou para a Seleção Brasileira.

Figura 3 - Rinaldo na Seleção Brasileira.

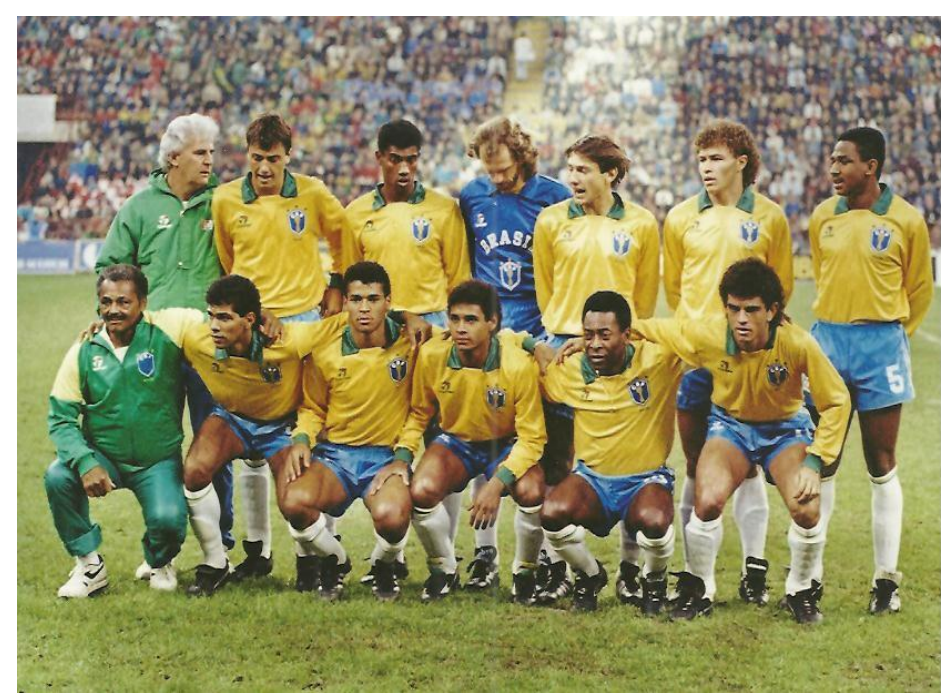

Fonte: Arquivo da CBF, 2011.

No começo dos anos 90, após ficar conhecido por ter sido "fominha" 5 no jogo que comemorava o $50^{\circ}$ aniversário do Rei Pelé, entre a Seleção Brasileira contra a seleção craques no estádio San Ciro, na Itália, no dia 31 de outubro de 1990, por não ter passado a bola para Pelé marcasse aquele que seria o gol de número 1.282 da sua carreira.

Ainda no início dos anos 90, Rinaldo retorna ao Brasil para jogar no São Paulo, mas nem pelas mãos do então treinador Telê Santana o ponta-esquerda voltou a brilhar, sendo dispensado pelo clube. Na equipe paulista, segundo o "Almanaque do São Paulo", Rinaldo fez 28 jogos, obtendo 12 vitórias, 8 empates, 8 derrotas, marcando apenas quatro gols.

Após a sua passagem pelo São Paulo, Rinaldo atuou por outros clubes do Brasil e do exterior, a exemplo do Sport Clube Recife, Portuguesa paulista, Marítimo e Moreirense de Portugal, Juventude do Rio Grande do Sul, além de equipes do México, Tunísia, Japão, Espanha, Grécia, China, Turquia, atuando por último no FC Kaernten, da Áustria, um de seus últimos clubes. Segundo alguns internautas, após encerrar sua carreira Rinaldo teria virado pastor evangélico e foi morar na cidade de Limeira - SP.

\footnotetext{
${ }^{5}$ O nome "fominha" é dado ao atleta que prende demais a bola e não costuma repassá-la aos colegas de equipe.
}

Nucleus,v.13,n.2,out.2016 
Assim como aconteceu Rinaldo, poucos anos depois outro paraibano, natural de João Pessoa, seguiria o mesmo destino e pela mesma razão que os anteriores seguiu para o Rio de Janeiro com a finalidade de trabalhar e ajudar a família que passava por uma grave crise financeira: Leovegildo Lins Gama Júnior - ou Júnior do Flamengo (Figura 4) e da seleção brasileira.

Nascido em João Pessoa em 29/06/1954, Júnior saiu da Paraíba ainda garoto ao lado de sua mãe. Oriundo do futebol de praia das areias de Copacabana, sua primeira escola, o atleta foi levado para o Flamengo aos 20 anos de idade e logo se tornou titular da lateral direita do clube da Gávea. ${ }^{6}$. Pelo Flamengo, Junior atuou de 1974 a 1984, conquistando vários títulos, inclusive o de Campeão Mundial Interclubes no Japão, em 1981.

Depois do Flamengo, Junior foi negociado com o Turino, da Itália, onde permaneceu até 1987, saindo para jogar como meio campista no Pescara, da cidade do mesmo nome, também na Itália, onde ficou até 1989, quando resolveu retornar para o Flamengo e jogou até 1993, sendo responsável no ano anterior pelo quinto título brasileiro do clube, o primeiro sem a presença de Zico, alcançando a marca de 800 jogos com a camisa do rubro-negro carioca.

As atuações pelo Clube de Regatas Flamengo renderam a sua convocação para a seleção brasileira, onde durante muito tempo foi referência atuando no meio de campo do selecionado nacional, tendo conseguido a incrível marca de 74 partidas disputadas, 43 vitórias, 17 empates e 9 derrotas, marcando 6 gols. Além disso, também esteve na seleção olímpica em 14 jogos e marcou um gol. Foi campeão do Torneio Pré-Olímpico de 1976 e da Copa da Amizade, em $1992^{7}$ (Confederação Brasileira de Futebol, 2011).

Figura 4 - Junior com uniforme da Seleção Brasileira.

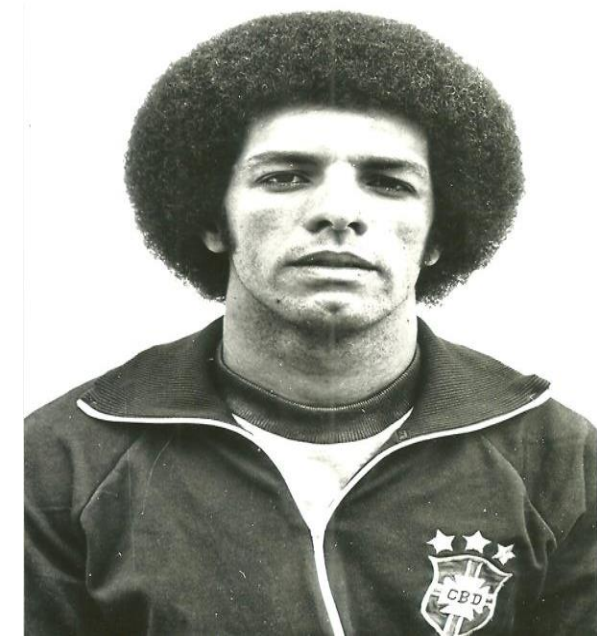

Fonte: Arquivo da CBF, 2011.

Reconhecido com um dos grandes ícones da história recente do Clube de Regatas Flamengo e da seleção brasileira, Júnior marcou sua história no futebol brasileiro como um dos grandes atletas de seu tempo.

Assim como Junior, outro atleta que obteve o mesmo sucesso atuando por clubes locais, do exterior e pela seleção brasileira foi Iomar do Nascimento - o Mazinho (Figura 5). Nascido na cidade Santa Rita, no dia 08 de abril de 1966, Mazinho é considerado o maior destaque entre todos os

\footnotetext{
${ }^{6}$ Idem, 2007.

${ }^{7}$ Idem, 2007, p. 51.
} 
jogadores paraibanos que do Estado saíram para brilhar no futebol mundial.

Revelado pela equipe do Santa Cruz da cidade de Santa Rita - PB, na década de 80, onde atuava como lateral esquerdo, Mazinho passou pela Seleção Paraibana Júnior e com 16 anos se transferiu para o Vasco da Gama, onde impressionava pela sua versatilidade, tendo por isso se destacado e conquistado vários títulos, fato que contribuiu para sua saída para o futebol europeu, onde fez bastante sucesso

Figura 5 - Mazinho Campeão do Mundo na Copa de 1994, nos Estados Unidos.

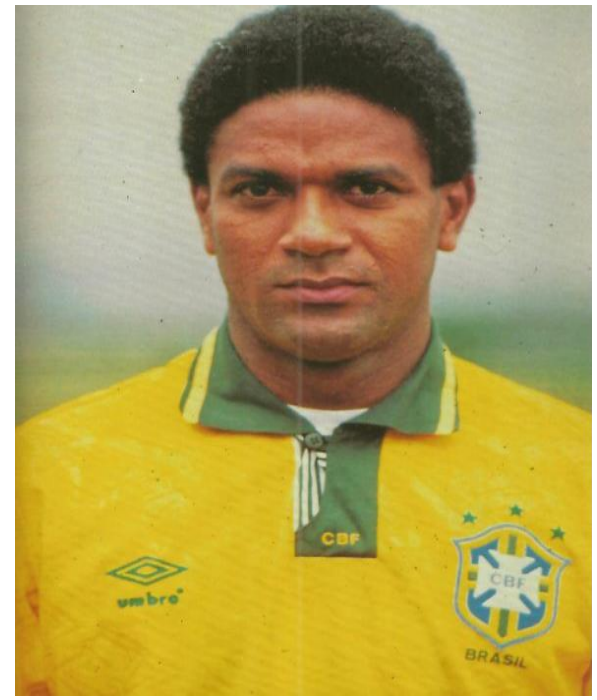

Fonte: Arquivo da CBF, 2011.

Na Europa, Mazinho atuou nas equipes do Lecce de 1990 a 1991; Fiorentina de 1991 a 1992; Valencia de 1994 a 1996; e Celta, em 1997. Em 2001, já com 35 anos, Mazinho retornou ao futebol brasileiro, onde voltou a atuar pelo Vasco e no final da carreira ainda teve uma passagem pelo Vitória da Bahia.

Em suas primeiras convocações para a seleção, foi um reserva capaz de atuar com eficiência em ambas as laterais, inclusive tendo jogado de lateral-direito na final da Copa América em 89, quando se sagrou campeão vencendo o Uruguai por 1 a 0 no Maracanã.

Mazinho participou de duas Copas do Mundo. Ficou no banco na Copa de 1990 e começou a Copa do Mundo de 1994, disputada nos Estados Unidos, como reserva, se firmando como titular do meio-campo da seleção tetracampeã mundial.

Ao contrário dos atletas acima, que se formaram nas divisas de base de clubes de futebol, jogadores como Marcelinho Paraíba, Fábio Bilica e, mais recentemente, Givanildo Hulk, foram revelados em escolinhas de base da Paraíba, e assim como os primeiros conseguiram se destacar no cenário nacional e internacional.

A história de muitos garotos oriundos da periferia das grandes cidades é bem parecida. Quase sempre são revelados por escolinhas que tem preocupação principal oferecer a formação do cidadão para o esporte e, principalmente, para a vida, a exemplo do que acontece com as escolinhas de futebol do Professor Luizinho Bola Cheia, em Campina Grande - PB, que já revelou diversos talentos para o futebol nacional, a exemplo dos citados no parágrafo acima.

Entre os atletas formados nas escolinhas de futebol local, Marcelinho Paraíba (Figura 6), como é mais conhecido, foi outro atleta que faz história no futebol paraibano e mundial. Com a idade de 14 anos e alguns meses, Marcelinho Paraíba surgiu numa peneira, no campo do Renascença, de fronte ao Estádio 
Plínio Lemos, onde atualmente existe a Vila Olímpica da Prefeitura Municipal do bairro de José Pinheiro. $\mathrm{Na}$ oportunidade, cerca de 100 meninos de vários bairros de Campina Grande compareceu ao peneirão divulgado através das emissoras locais, Rádio Borborema e Caturité no dia 10 de maio de 1989.

Filho de Pedrinho Cangula, ex-artilheiro do Campinense Clube e de outras equipes do Piauí e Alagoas, Marcelinho Paraíba nasceu no bairro de José Pinheiro, em Campina Grande, no dia 17 de maio de 1975. Formado juntamente com Claelson, Tony, Dó, Jajá e Luciano Chimbel nas escolinhas do professor Manoel Luis Melo - Luizinho Bola Cheia, como é mais conhecido, Marcelinho foi um dos destaques, fato que contribuiu para sua ascensão ao futebol profissional, mais precisamente para o Campinense Clube, onde foi bicampeão paraibano.

Depois de passar pelo Campinense Clube, o atleta foi negociado para o Sport Clube Recife, onde passou a se destacar no cenário do futebol brasileiro. Entre 1994 e 1995 teve uma rápida passagem pelo Santos Futebol Clube, sendo negociado dois anos mais tarde para o São Paulo Futebol Clube, onde foi o grande destaque, tendo conquistado dois títulos antes de ser vendido para o Olympique de Marseille, da França, no qual ficou por apenas um ano, 2001, retornando ao Brasil para atuar na equipe do Grêmio portoalegrense, quando começou a viver o auge de sua carreira, tornando-se ídolo dos torcedores gremistas.

Campeão e artilheiro do Campeonato Gaúcho e também da Copa do Brasil quando marcou um gol no segundo jogo da final contra o Corinthians, não chegou a atuar pelo Campeonato Brasileiro daquele ano, já que acabou conseguindo um contrato de cinco anos com Hertha Berlin, da Alemanha, clube modesto que ajudou a conquistar os títulos da Copa da Liga Alemã de 2001 e 2002, fato que acabou lhe rendendo o convite para a Seleção Brasileira.

As conquistas acima ainda renderam ao atleta a eternização de sua trajetória no futebol alemão, através da cineasta carioca Ana Azevedo, que esteve na Alemanha em fevereiro de 2005, quando foi selecionada para participar do "Talent Campus Festival de Berlim" e escolheu o futebol como tema de um filme com o qual concorreria às premiações do certame em 2006, cujo roteiro era baseado na história do paraibano Marcelinho Paraíba.

Figura 6 - Marcelinho na Seleção Brasileira

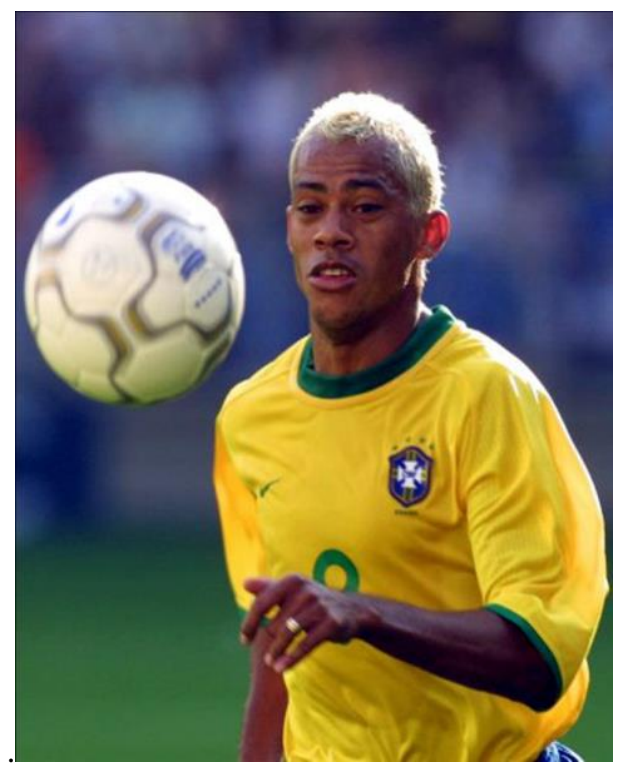

Fonte: Arquivo da CBF, 2011. 
Segundo o Jornal A Palavra (2005), declaradamente amante do futebol, Ana Azevedo passou a pesquisar sobre a prática desse esporte na capital alemã e, para sua grata surpresa, logo percebeu que seria impossível dissociar a figura de Marcelinho Paraíba do futebol jogado na Alemanha, o que acabou lhe rendendo destaque no festival.

Seguindo a trajetória vitoriosa de Marcelinho Paraíba, Fábio Bilica(Figura 7) foi outro atleta também formado nas escolinhas de futebol do professor Luizinho Bola Cheia, que saiu de Campina Grande para ganhar o mundo e fazer igual sucesso. Garoto pobre do bairro das Malvinas e criado pelos avós, devido à ausência do pai, que não o acompanhou, foi descoberto no ano de 1995 em meio a vários colegas de infância que com ele se apresentaram para participar de um treino realizado no período vespertino às $4^{\mathrm{a}}$ e $6^{\mathrm{a}}$ feiras das 14 às 17 horas, no campo do Colégio Estadual da Prata - chamado de "O Gigantão".

Com 15 anos de idade, 1.85 de altura, e traços de craque, Bilica foi de imediato escolhido para ser levado para um período de testes no Esporte Clube Vitória da Bahia, fato que só foi possível devido ao apoio de sua mãe Lúcia (cabeleireira), que deu a autorização ao professor Luizinho Bola Cheia para que o garoto viajasse a Salvador. Já no Vitória, no primeiro treino com bola, Fábio Bilica foi aprovado pelo superintendente do Vitória Newton Mota.

Nas divisões de base do Esporte Clube Vitória o rendimento do garoto cresceu assustadoramente de produção, o que acabou lhe rendendo a convocação para atuar pela seleção brasileira sub 17, 19. No entanto, o atleta só se tornou realmente conhecido no Brasil quando foi convocado pelo então técnico da Seleção Brasileira, Wanderley Luxemburgo, em 1999, para as disputas do torneio Pré-Olímpico.

Figura 7 - Fábio Bilica com o troféu da Copa de Sidney, nos Estados Unidos.

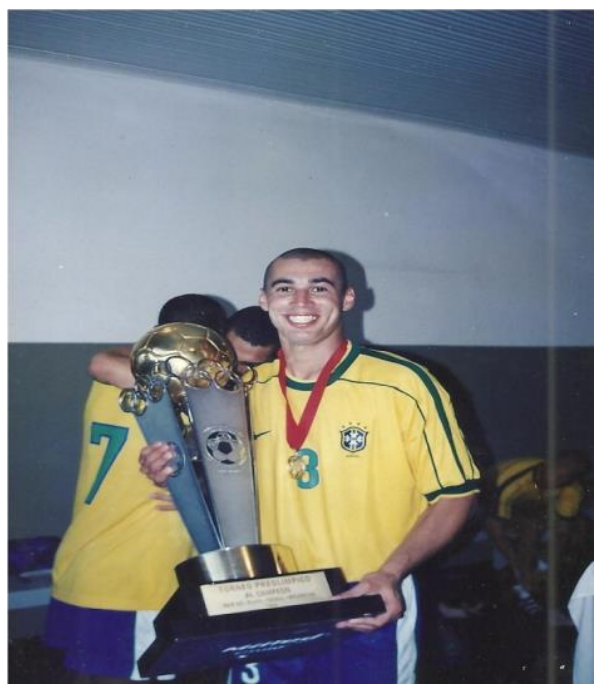

Fonte: Arquivo próprio.

Para disputar as olimpíadas, Fábio Bilica precisava da autorização de seu clube que não queria liberá-lo. O esforço acabou não sendo premiado, pois o Brasil caiu nas quartas de final para a seleção de Camarões. Apesar disso, o atleta teve a sua permanência mantida no elenco da seleção que disputou a Copa do Mundo de Sidney, nos Estados Unidos. Depois de atuar por equipes da Itália e da França, o atleta seguiu a sua carreira jogando no futebol turco, onde permanece atualmente.

Copiando a história de seus conterrâneos da Paraíba, Givanildo Hulk (Figura 8 ) foi outro atleta que despontou nos últimos anos do futebol internacional para a seleção brasileira. Tendo iniciado a sua carreira no futebol de várzea, Hulk, como é mais conhecido, com 13 anos de idade foi trazido para a escolinha do professor Luizinho Bola Cheia, após uma peneira realizada na pelada de "Tia Chica", em 
1999. "Enquanto admirava o pequeno talento jogar, esperei acabar o rachão para convidá-lo para fazer parte da Escolinha Bola Cheia do SAFEPB da qual sou o responsável até hoje”, afirma Luizinho Bola Cheia.

No ano de 2000, o Sindicato dos Atletas de Futebol do Estado da Paraíba - SAFEPB, o convidou para as disputas da Copa Gazetinha, na cidade de Ibiraçú-ES, que contava com a participação de vários Estados brasileiros, uma espécie de Copa do Brasil Infanto-juvenil, competição pela qual jogamos cinco partidas oficiais. Com a permissão de seus pais, o marchante Gilvan e dona Socorro (manicure), Hulk, então com 14 anos, foi levado para o torneio onde jogou as cinco partidas como titular, chamando a atenção de vários empresários que logo se interessaram pelo mais novo talento do futebol paraibano, querendo levá-lo para São Paulo, Rio de Janeiro. No entanto, este acabou sendo levado para o Vitória da Bahia onde se destacou e foi emprestado ao Kawasaki Frontale, do Japão, que no ano seguinte compraria seu passe. Após ficar no clube durante o resto do ano, foi emprestado para o Consadole Sapporo, onde se destacou nacionalmente, marcando 25 gols na temporada, terminando na vice-artilharia da segunda divisão japonesa.

Em 2007 foi mais uma vez emprestado, dessa vez ao Tokio Verdy, também da segunda divisão, tendo marcado no certame quase 40 gols, sagrando-se artilheiro da competição, fato que ajudou o seu clube a ascender de volta à elite do futebol japonês, que resolveu comprar o seu passe para a temporada seguinte, depois de ter voltado para o Kawasaki e atuado algumas vezes.

A passagem de Hulk pelo Tokio Verdy foi rápida. Após um começo eficiente com 7 gols em 11 partidas, o atleta transferiu-se para o Futebol Clube do Porto de Portugal, que adquiriu 50\% dos direitos econômicos do atleta e 5,5 milhões num contrato válido por quatro temporadas. Nas duas primeiras temporadas no clube português não marcou muitos gols, mas o bastante para chamar a atenção dos mais diversos clubes e dirigentes do mundo, fato que contribuiu para a sua convocação para a Seleção Brasileira, onde chegou apontado como uma das dez maiores promessas europeias na temporada 20082009, tendo o seu contrato prolongado até 2014.

O resultado da valorização do atleta veio rápido e a cláusula de rescisão que antes estava fixada em R \$ 40 milhões subiu para R \$ 100 milhões, considerada a mais alta da história futebol português. A sua cotação subiu rapidamente em um ano, tornando-o numa das estrelas do futebol europeu em parte devido à campanha do clube na Liga dos Campeões 2009-2010. A temporada de 2010/2011 o atleta começou em plena forma, marcando dezesseis gols nos primeiros dezesseis jogos em que atuou.

Figura 8 - Hulk atuando pela Seleção Brasileira.

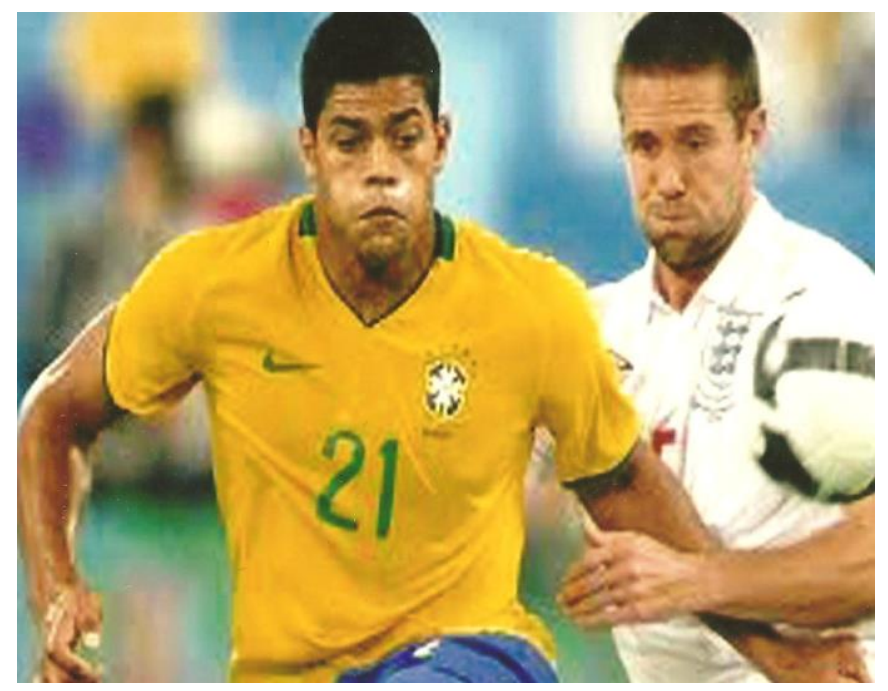

Fonte: arquivo próprio, 2011. 


\section{CONCLUSÃO}

O futebol que tantos craques revelou nos chamados campos de várzea do Brasil perdeu espaço com o decorrer dos anos para o desenvolvimento urbano, passando cada dia mais a ser praticado e desenvolvido no ambiente das escolinhas de futebol que se espalharam pelo país.

Embora alguns analistas como Wilpert (2005) e Scaglia (1999) admitam que estas mudanças têm a ver com a visão distorcida de alguns pais que querem ver seus filhos ricos e famosos e da política mercantilista empregada por alguns coordenadores destas escolinhas que pensando em levar vantagem financeira mal formam os atletas e já os negociam com clubes em geral do exterior, acreditamos que de maneira geral as escolinhas têm cumprido o seu papel na formação e desenvolvimento dos novos atletas do futebol brasileiro.

O papel que vem sendo desempenhado pelas escolinhas ganha mais respaldo quando se sabe que ao contrário das outras que visam o lucro, a maioria das escolas de futebol não está preocupada com a vantagem financeira, mas com a formação do homem, do cidadão, como é o caso das escolinhas que estão sob o comando do professor Luizinho Bola Cheia que tantos atletas já formou para o futebol brasileiro e internacional, a exemplo de Fabio Bilica, Marcelinho Paraíba e Givanildo Hulk que hoje fazem sucesso no cenário do futebol mundial, este último inclusive vestindo a camisa da seleção brasileira.

Muitos atletas são unânimes em ratificar a contribuição das escolinhas para a sua formação como atleta, cidadãos de caráter, dignos de respeito e de um lugar ao sol, que muitas vezes lhes é negado pela própria condição de vida que acabam herdando da família, em geral pessoas de baixa renda e sem a menor condição de oferecer-lhes um futuro melhor, como frequentemente ocorre na Paraíba.

Diante de tal realidade, observa-se a necessidade do governo e da sociedade se unir em torno de um projeto de criação de escolinhas pelo Brasil, como forma de minimizar e/ou tentar resolver alguns problemas que o país vem enfrentando na educação, por exemplo, com as altas taxas de evasão escolar e, ainda, a violência e as drogas.

Boa parte dos recursos que hoje são desviados pela corrupção poderiam ser utilizados na construção de escolinhas de futebol em todo o Brasil como forma de combate a evasão escolar, à violência e o uso de drogas, contribuindo assim para a formação de atletas-cidadãos com um futuro melhor pela frente.

\section{REFERÊNCIAS}

BIELINSKI, R. P. Escolinha de futebol: ensino com emoção. Rio de Janeiro: Grupo Palestra Sport, 136 p. N.d.

GIL, A. C. Métodos e técnicas de pesquisa social. 5. Ed. São Paulo: Atlas, 2004.

MELO, M. L. Futebol também se aprende na escola. João pessoa - PB, CFT, 2004.

SCAGLIA, A. J. O Futebol que se aprende e o futebol que se ensina. 1999. Dissertação de Mestrado. Universidade Estadual de Campinas - UNICAMP.

TOSCANO, A. Na boca do gol - andanças de um narrador esportivo. 22. ed. Campina Grande: UEPB, 2007.

WILPERT, R. A. O futebol como agente de inclusão e interação social: um estudo de caso sobre as escolinhas de futebol de Florianópolis. Dissertação (Mestrado). Florianópolis - SC, 2005. 